\title{
«LA HISTORIA DE LOS DOS ENAMORADOS DE LA PEÑA DE ANTEQUERA» EN EL PARA ALGUNOS DE MATÍAS DE LOS REYES: FUENTES Y REELABORACIONES
}

\author{
Alba Gómez Moral \\ Universidad Nacional de Educación a Distancia \\ albagomo@gmail.com
}

\section{INTRODUCCIÓN}

a historia de la peña de los dos enamorados de Antequera», leyenda
de vasta trayectoria literaria, forma parte de la novelística breve in-
serta en la última obra de Matías de los Reyes, Para algunos (Madrid, viuda de Juan Sánchez, 1640). A partir de este asunto legendario de raigambre popular y cincelado, no obstante, en cuantiosas versiones y géneros -algunas de ellas realizadas incluso fuera de las fronteras hispánicas (Lara Garrido 1982: 174; Menéndez Pelayo 1944: 154)-, Matías de los Reyes inaugura la recreación de esta leyenda en el molde de la prosa breve de ficción.

Con anterioridad a esta novela corta, la tradición previa se había basado en hormas épicas o historiográficas, y, en efecto, el Poema heroico del asalto y conquista de Antequera de Rodrigo de Carvajal y Robles (Lima, 1627) se halla en el origen de la novela de Matías de los Reyes. Amén de este poema épico, no faltan en la aludida novela corta ingredientes que remedan a las novelle de Giovanni Boccaccio así como a la «Historia de los dos enamorados Ozmín y Daraja», novela morisca imbricada en el Guzmán de Alfarache (1599). Junto a esta relación de influjos conviven en la trama narrativa rasgos originales -al menos no incluidos en el resto de versiones cotejadas- que van a permitir constatar y ubicar la lectura y proyección de «La historia de la peña de los enamorados de Antequera» de Matías de los Reyes en una de las múltiples versiones de la leyenda que se llevaron a cabo en el Romanticismo hispánico: la novela «La peña de los enamorados» de José Heriberto García de Quevedo, publicada en dos entregas en el Museo de las Familias en 1850.

Edad de Oro, XXXV (2016), pp. 251-267, ISSN: 0212-042 - DOI http://dx.doi.org/10.15366/edadoro2016.35.015 


\section{La leyenda de los dos enamorados de la PeÑa de ANTequera}

La naturaleza popular, historiográfica, literaria e incluso mixta de las fuentes que se han hecho eco de esta leyenda vinculada con la reconquista de Antequera por parte del infante don Fernando, dificulta la realización de un nítido bosquejo cronológico que dé cuenta de versiones, relaciones e influjos (Lara Garrido 1984: 143). Dada, por otra parte, la ingente cantidad de testimonios que atesora alguna versión de la leyenda, se verán aquí mermados y reducidos a los más señeros y relevantes en relación con la novela corta incluida en el Para algunos de Matías de los Reyes.

La primera constatación textual de esta leyenda antequerana figura en Historiarum Ferdinandi Regis Aragoniae Libri tres (1445-1457) del humanista Lorenzo Valla (López Estrada 1957: 17-18; Lara Garrido 1984: 143, Menéndez Pelayo 1944: 153), cuyo asunto alcanzará no escasa resonancia al ser incluido -asimismo en un molde historiográfico- por el padre Juan de Mariana en su difundida Historia general de España (1601). Esta primera versión escrita de la leyenda, que será objeto de multitud de recreaciones literarias de asunto fronterizo, recoge los amores desdichados entre un cristiano esclavo al servicio de un moro de Granada y la hija de este, de los que no se detallan los nombres. La novedad que esta leyenda aporta al género morisco estriba en la desemejanza religiosa, puesto que los amantes, paradójicamente, rinden culto a dioses distintos (Lara Garrido 1984: 142; Carrasco Urgoiti 1989: 71), por lo que deciden fugarse a territorio cristiano. El padre de ella, al enterarse, sale en su busca y cuando están a punto de ser alcanzados, se refugian en la peña de Antequera y acuerdan, antes de ser capturados, lanzarse al vacío desde lo alto de aquel promontorio. Esta es la historia que conocemos a partir de los textos más antiguos que la conservan y sobre la que se han realizado numerosas versiones a lo largo del tiempo, como veremos más adelante. Junto a ella, existe otra rama, más vinculada a la tradición oral de la leyenda, que es la que relata Juan de Vilches en su poema latino en dísticos elegíacos «De rvpe dvorum amantivm apvd antiqvariam sita, ad litteris praestatem virvm dominvm Fabianvm Nebrissensem» (De variis lvsibus sylva, 1544). En este caso, Hamet, siervo del rey de Granada, y Tagzona, oriunda de Archidona, se ven por primera vez en una fuente y caen rendidos al amor. Hamet invita a Tagzona a marcharse con él en su yegua y así lo ejecutan. Quienes presencian la escena consideran que la muchacha ha sido raptada, noticia que llega a oídos de su padre, quien, acompañado por una multitudinaria tropa, sale en su búsqueda. Una vez que el progenitor advierte, ya en la peña de Antequera, que la joven no va forzada sino voluntariamente, decide abandonar la persecución y desandar sus pasos, lo que no evitará el funesto desenlace: Hamet acaba asesinado a manos de unos pastores, por lo que Tagzona decide quitarse la vida con la espada de su amado. A esta rama escrita, 
también trágica, fundada por Juan de Vilches se suman muy pronto escritores como Agustín de Tejada (Martos Pérez 2008: 146-190).

3. «La historia de la peña de los dos enamorados de Antequera»: un Caso PARTICULAR ENTRE LA NOVELÍSTICA BREVE DEL PARA ALGUNOS

El atractivo de una historia como esta no pasó desapercibido a los ojos de un narrador avezado y gran lector como Matías de los Reyes, quien quiso recrearla en su Para algunos. De hecho, «La historia de la peña de los dos enamorados de Antequera» resulta la más exclusiva de las siete novelas cortas que aparecen en esta obra: es la única que integra una unidad estructural independiente -el discurso cuarto-, que ostenta título y que, a diferencia del resto, no hunde sus raíces en la novella italiana Della metamorfosi cioè trasformazione del virtuoso (Orvieto, Rosato Tintinassi, 1582).

A pesar de estas diferencias, comparte con las demás narraciones su doble propósito: la utilidad y el deleite en sintonía con las exigencias culturales de la época. En relación con su carácter instructivo - manifiesto de formas diversas y no aplicable exclusivamente al ámbito de la moral-, algunas de ellas se engarzan a la narración principal con el fin de ilustrar algún razonamiento expuesto en la misma, y esto es precisamente lo que ocurre con el caso que nos ocupa. De modo que en el discurso segundo -de los trece que conforman el total de la obra-, Acrisio, el protagonista, como parte de sus memorias, asegura que se enamoró de oídas de la hermosa Olimpia sin haberla visto jamás, solo a partir de la audición de sus atributos, cauce de enamoramiento presente en versiones anteriores de la leyenda ${ }^{1}$ y asimismo asunto de larga tradición literaria ${ }^{2}$. La suspicacia que esta entrada de amor genera en los tertulianos que escuchan a Acrisio mueve a este a alegar lances similares mediante la autoridad de Boccaccio: «d'este parescer fue el Certaldo

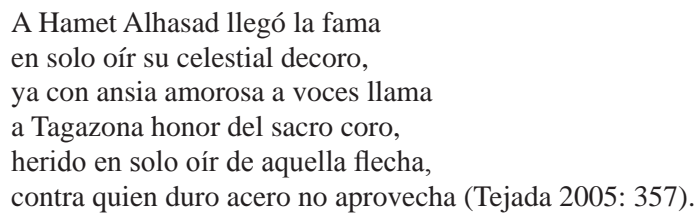

El enamoramiento de oídas también está presente en la versión de Juan Bautista de Mesa (Martínez Bennecker, 2008: 245).

2 En efecto, este asunto gozó de una incidencia nada baladí en las colecciones de novela corta del seiscientos, y así lo verifica su presencia, entre otros, en El Menandro (Jaén, Francisco Pérez de Castilla, 1630) del propio Matías de los Reyes, en la novela corta Al cabo de los años mil inserta en el Para todos (1632) de Juan Pérez de Montalbán, o en el Deleitar aprovechando (1635) de Tirso de Molina, quien atestiguaba que «entrando amor por los oídos y la sensualidad por los ojos, tanta más ventaja llevan aquellos a estos, cuanto va del alma al cuerpo» (1994: 92-93).

Edad de Oro, XXXV (2016), pp. 251-267, ISSN: 0212-0429 
en la novela de Ludovico y en la del Gerbino» (1640: 57v) ${ }^{3}$-aspecto sobre el que tornaremos a continuación-, no sin antes dejar prometido un relato que corroborará, del mismo modo, su opinión. Habrá que esperar hasta el discurso cuarto para conocer la historia de los dos enamorados de la peña de Antequera. Por tanto, con dicha novela corta, de acuerdo con este debate sobre el enamoramiento de oídas, el protagonista pretende validar su existencia.

El pretexto que engasta la narración de esta novela corta en el Para algunos lo genera el encuentro de Acrisio con dos españoles: el antequerano Alarcón y Roberto, quien le pide a aquel que cuente una leyenda conocida sobre su tierra natal. Alarcón acepta la propuesta pero antes deja claro que «la certeza y verdad [...] que tenga esa historia no está averiguada más de por lo que publica una vulgar y común tradición» (1640: 71v). La apostilla marginal en la que puede leerse «Mariana en su Historia general de España» nos llevaría a pensar en este texto como fuente directa; sin embargo, el cotejo de las distintas versiones de la leyenda desvela que no fue tal la que recreó Matías de los Reyes sino la inserta en el Poema heroico del asalto y conquista de Antequera de Rodrigo de Carvajal y Robles, que, por lo demás, fue ampliamente conocida durante el Barroco (Lara Garrido 1984: 147). Nos mueve a esta consideración, aparte de las pruebas textuales, el hecho de que la versión de Mariana es muy escueta y, además, no introduce los nombres de los protagonistas, como sí hace Matías de los Reyes, homónimos a los de Carvajal y Robles. En este sentido, el poema heroico aporta cuantiosas novedades con respecto a los testimonios anteriores de la leyenda antequerana, elementos que perdurarán en ulteriores versiones de la historia como lo refrenda el Para algunos de Matías de los Reyes.

Una de estas primicias la conforma el estatus social del joven cristiano, al que Rodrigo de Carvajal y Robles emparenta con la nobleza astigitana, si bien con anterioridad este mismo personaje no dejaba de ser bien un cristiano cautivo o bien un musulmán, Hamet, pero jamás de ascendencia patricia. De manera que en el canto IV del poema de Robles se lee:

Nació en Écija un joven de la casa

ilustre de Aguilar, llamado Tello,

con quien naturaleza no fue escasa [...] (2000: 148)

Una información similar a la que aparece en las primeras líneas del discurso cuarto del Para algunos: «Écija hoy, y corazón de la Vandalia, engaste de la andaluz nobleza y patria también de don Tello de Aguilar, descendiente de la ilustre familia que con este apellido se decora [...]» (1640: 72v).

3 Puntúo y modernizo las grafías de las citas del Para algunos de Matías de los Reyes según usos actuales. 
Ciertamente, entre las aportaciones del autor épico se cuentan nuevos personajes, algunos de ellos históricos y otros ficcionales, tales como el judío Levi, cuya relevancia en la trama de estas versiones se revela incuestionable: a partir de la descripción de la joven Ardama que realiza el hebreo, don Tello queda completamente enamorado. Para lograr un acercamiento y satisfacer sus amores, contará con la complicidad de Levi:

[54] Mas para cotejar este retrato con la original propia hermosura de Ardama quiero hacer contigo un trato, que a ti dará ganancia, a mí ventura; $[\ldots]$ [55] Yo he de fingirme esclavo; tú, mi dueño, y a Granada hemos de ir, donde vendido a su padre de Ardama o en empeño me has de dejar o con algún partido, de suerte que yo pueda deste sueño despertar, en que estoy adormecido; porque si deste sueño no despierto, tanto es estar dormido como muerto (Carvajal 2000: 149).

Algo muy similar a lo que sucede en el Para algunos:

quiero que sepas que de la ingeniosa descripción que hiciste hoy de la belleza de Ardama le comunicó a mi libre pecho tal incendio de amor, que si tú mesmo, que dispusiste mi daño, no previenes mi remedio, puedes acusarte de homicida mío, como remediándome, gloriarte del nombre de mi restaurador. Mira si te atreves a mi ayuda y finge en tu imaginación el premio, que el que te prometieres tendrás de mí con largueza. [...] Lo que intento, caro amigo, es que me lleves a Granada con nombre de esclavo tuyo y me vendas a Abenabo, padre de la bella Ardama. Pues con tan ingeniosa introdución, yo llegaré a verla y después en el resto de mis esperanzas, Amor, que supo instruirme en esto, sabrá disponer lo demás (Reyes, 1640: 74v).

Las similitudes referidas entre la leyenda recreada por Rodrigo de Carvajal y Robles y su imitación por parte de Matías de los Reyes, de las que en las líneas anteriores solo se ha recogido una escueta muestra, no figuran en el bosquejo del padre Mariana que, como se apuntaba, comparece en los marginalia del Para algunos. Asimismo, una prueba añadida corrobora la lectura del poema épico por parte de Matías de los Reyes y tiene lugar en el discurso segundo del Para algunos, en el seno del aludido coloquio en torno al enamoramiento de oídas. En esta ocasión Acrisio echa mano de un «poeta de nuestros tiempos» que, como afirma 
el protagonista, también había tratado este asunto en sus versos, de los que incluye una muestra:

El amor se le entró por los oídos, porque del alma son también las puertas, como los ojos (estos dos sentidos) que velando y durmiendo están abiertas, etcétera (Reyes 1640: 57r).

Efectivamente, dichos versos forman parte de la octava XLIV del cuarto canto del Poema heroico del asalto y conquista de Antequera, y aparecen referidos, como no podía ser de otra manera, a don Tello de Aguilar, aunque descontextualizados en este caso y lejanos en el texto de la aparición de este personaje en el Para algunos -que no acontecerá, como se decía, hasta el discurso cuarto.

Además de las evidentes y múltiples concomitancias entre ambos testimonios, el Poema heroico del asalto y conquista de Antequera, pese a ser el principal, no fue el único texto que el autor del Para algunos tomó en consideración en el momento de recrear la leyenda de los enamorados de la peña de Antequera. Optó también por condimentar su versión con elementos que emulan tanto a una de las novelle de Boccaccio -la de Ludovico [VII,7], previamente referida- como a la «Historia de los enamorados Ozmín y Daraja», novela corta entreverada en el Guzmán de Alfarache, cuyo influjo se atisba ya desde el propio título. En relación con la obra de Mateo Alemán y más allá de esta similitud, habría que decir que ambas novelas cortas se insertan en un formato narrativo extenso a partir de un motivo análogo. Así, en el Para algunos, Alarcón, el narrador de la leyenda, destaca el carácter lúdico de la historia «remitiendo para el entretenimiento del camino la narración», con la que promete «un entretenido rato en la novedad del suceso» (1640: 71v). De manera semejante, en el Guzmán de Alfarache (I,7), un joven clérigo cuenta «La historia de los dos enamorados Ozmín y Daraja» -emplazada en la Sevilla de la Reconquista-, con el fin de «entretener el camino con algún alivio» (Alemán 2009: 213). Ambos protagonistas, Acrisio y Guzmán, asisten como receptores a sendas tramas moriscas en las que también podemos encontrar similitudes. Y es que ambos coprotagonistas masculinos, tanto Ozmín como don Tello, se valen de idéntico subterfugio para encauzar sus amores: simular un rango social inferior para trabajar como jardineros en los vergeles de sus amadas ${ }^{4}$. Sobre esta relación resulta sumamente sugestivo el razonamiento que verbaliza Alarcón, el narrador de los amores de don Tello y Ardama en el Para algunos: «es ya pensión de los amantes venturosos el servir este oficio en los jardines de sus

4 En el Poema heroico del asalto y conquista de Antequera don Tello es comprado como esclavo por Abenabo, padre de Ardama, pero no existe ninguna referencia a la profesión de jardinero que acaba desempeñando en el Para algunos: «[58] por esclavo se dio a la tiranía / del judío, y él mismo por esclavo / lo vendió al sagacísimo Abenabo» (2000: 149). 
damas. Debe de ser porque en ellos tiene el amor sus cortes [...]. Y si no es esto, será porque sus cronistas lo quieren así» ${ }^{5}$ (1640: 76r).

En la versión de la leyenda antequerana de Matías de los Reyes se hallan igualmente influencias procedentes de la novella número VII de la séptima jornada del Decamerón, que tiene por protagonista a Ludovico, personaje a quien el propio Acrisio había mencionado, ya en el segundo discurso, mientras discurría sobre la entrada del amor por los oídos. En la antología boccacciana relata Filomena, una de las narradoras, lo siguiente:

mezclándose en una conversación de los jóvenes entre los que estaba Ludovico [...] y oyéndolos razonar entre sí sobre las damas hermosas de Francia y de Inglaterra y de otras partes del mundo, comenzó uno de ellos a decir que ciertamente de cuanto mundo él había recorrido y de cuantas mujeres había visto, nunca una hermosura semejante a la mujer de Egano de los Galluzzi de Bolonia, llamada doña Beatriz, había visto; [...] la cual cosa escuchando Ludovico, que todavía no se había enamorado de ninguna, se inflamó en tanto deseo de verla que en otra cosa no podía fijar el pensamiento; [...] dispuesto a ir hasta Bolonia a verla, y allí quedarse si a ella le placía (2001: 802)

Algo muy semejante le sucede a don Tello de Aguilar en la novela corta de Matías de los Reyes:

estaba don Tello un día en una conversación de caballeros de su edad y alientos, y entre otras materias que entre ellos se trataba, se discurrió una sobre los sujetos hermosos de las damas de aquella su ciudad, haciendo cada cual alarde de las partes más laudables que en la dama que celebraba tenía observadas. Solo don Tello era oyente destos amorosos asuntos, sin que él entrase a la parte de las alabanzas de alguna dama, ocasionando con esta esquiveza a que los demás le diesen trato con los atributos y epítetos que suelen imponerse y atribuirse a los galanes de su edad, que no tienen voto en semejantes prácticas. Pero él se reía de todos, gloriándose de la libertad que gozaba en virtud de su retirada opinión. [...] A esta conversación se halló también un hebreo, llamado Levi, [...] el cual oyendo tantas alabanzas de las cristianas damas, dijo: «si yo os pintase la de las damas granadinas, quedaríades desengañados de que no se cifra en Écija la hermosura de toda la Andalucía» [...]

\footnotetext{
A este respecto no deja de sorprender el comentario condenatorio hacia las novelas por parte de Ambrosio Bondía en su Cítara de Apolo y Parnaso en Aragón (Zaragoza, Diego Dormer, 1650), reprobación en la que se ve salpicado el jardín: «en casi todas [las novelas] dicen con descrédito grande, que [las doncellas] se han huido de las casas de sus padres por jardines, siendo verdad, que por más amor que hayan tenido, ninguna se atrevió a sacar el pie de las casas paternas. [...] Por tanto, se ha decretado que ninguna de estas novelas ni otras que no mudaren de estilo con ingenio y arte, sean recebidas en el deliciosísimo Parnaso, y que los padres que tuvieren hijas, no tengan en sus casas jardines, porque si llegan a noticia de estos semicómicos tremendos, sin reparar en tan enorme y temerario juicio, se atreverán a decir que se salieron por allí» (f. 604).
} 
Atento oyó don Tello la descripción que Levi hacía de la bella mora, ya menos libre de los amorosos incursos que cuando blasonaba su libertad (1640: 73r-v).

En esta ocasión, el contexto narrativo en el que don Tello se enamora de oídas de Ardama evoca una situación análoga a la que figura en la aludida novella, de manera que la narración, en este punto, se desvía con respecto a su fuente principal -el poema heroico-, en la que se lee a propósito del enamoramiento de don Tello:

[43] Este, por la desgracia de su estrella

o por lástima triste del oyente,

a quien viniere la noticia della,

inflamado se vio de amor ardiente,

que oyendo celebrar de Ardama bella

la beldad de aquel siglo más luciente,

por relación de un mercader judío,

la fuerza le entregó de su albedrío (Carvajal 2000: 148).

El poema épico de Carvajal y Robles se muestra más escueto en este aspecto y carece tanto del contexto social en que se halla inmerso don Tello en el Para algunos como de la impunidad del joven al amor hasta el momento previo a la audición de los atributos de Ardama. Dichos elementos proceden de la referida obra boccacciana donde Ludovico, protagonista de la novella, también acaba siendo esclavo del marido de Beatriz, su amada, con el fin de aproximarse a ella.

Por más que Matías de los Reyes se valiese de varias fuentes a partir de las cuales confeccionó su propia versión, lo cierto es que pareció mostrarse ligeramente original en algunos aspectos argumentales, y son precisamente estas divergencias no constatadas, hasta el momento, en otros testimonios ${ }^{6}$ las que nos dan licencia para validar el influjo de la novela corta incluida en el Para algunos en la novela romántica por entregas «La peña de los enamorados» de José Heriberto García de Quevedo.

6 $\quad$ Dadas las prácticas de escritura de Matías de los Reyes, se ha de tener especial cautela a la hora de atribuirle contenidos originales. Menéndez Pelayo, por ejemplo, apuntó que «don Bartolomé José Gallardo afirmaba haber poseído y perdido una comedia de Tirso de Molina sobre la peña de los enamorados. La que existe manuscrita con aquel título, por ningún concepto puede pertenecer a tan excelso dramaturgo» (1944: 156). Efectivamente, la anónima comedia La peña de los enamorados (BNE, Mss./ 14745) [s.a.] [s.i.] [s.l.] recoge la versión de tradición escrita iniciada por Lorenzo Valla y difundida por el padre Mariana (y así consta en sus versos finales: «con esto, senado ilustre / tiene fin esta tragedia / que a más elegantes luces / escribió el padre Mariana / cuyo risco se descubre / no muy lejos de Antequera / en los campos andaluces» (f. 82v). Dicho testimonio puede descartarse sin lugar a dudas como origen de las innovaciones argumentales que figuran en la novela corta del Para algunos, pese a que la información expuesta vinculada con Tirso de Molina genere ciertas suspicacias. 
4. «La Peña de los enamorados» de José Heriberto García de Quevedo: entre la épica de Rodrigo de Carvajal y Robles y el Para algunos de Matías de los Reyes

La leyenda antequerana de estos trágicos amantes gozó en el Romanticismo hispánico de un auge sin precedentes y buena prueba de ello la otorga el ingente volumen de versiones que proliferaron engalanadas en moldes literarios diversos (Jiménez Morales 1996; Rodríguez Gutiérrez 2002: 128; Rodríguez Gutiérrez 2004: 58; Miranda 2005: 51-52, et alii). En el ámbito narrativo, y además de las versiones de Joseph Marie de la Croix (1796), Mariano Roca de Togores (1836), Manuel de Zúñiga (1839) o Miguel Menéndez Arango (1842), José Heriberto García de Quevedo, literato y diplomático venezolano, publicó «La peña de los enamorados» en el Museo de las Familias en dos entregas: el 25 de febrero (partes primera y segunda) y el 25 de marzo de 1850 (parte tercera). En palabras de Jiménez Morales, la narración de García de Quevedo «sigue en todo momento el Poema del asalto y conquista de Antequera de Carvajal y Robles. Cambia, eso sí, algunos motivos del relato y su estructura, al emplear la prosa» (1996: 232). Ciertamente, la colación de los testimonios pone a la vista el poema épico como base indudable de la novela de García de Quevedo, en especial en los motivos principales de la leyenda, aunque su lectura atenta parece manifestar una fuente alternativa: «La historia de los dos enamorados de la peña de Antequera» enmarcada en el Para algunos. Las discrepancias, pues, a las que alude Jiménez Morales, no serían más que recreaciones cuyo origen podría remontarse a la novela corta de Matías de los Reyes.

Ante la ausencia de ediciones del Para algunos más allá de la prínceps -lo cual parece evidenciar su escasa repercusión literaria no solo en el seiscientos sino también en siglos posteriores-, resulta cuanto menos oscuro el vínculo entre la narración de García de Quevedo y la novela corta de Matías de los Reyes. A no ser que se eche mano de Francisco Javier de Burgos y Olmo, poeta, periodista y político granadino, apasionado de la literatura española del Siglo de Oro. En efecto, en distintos números de La Alhambra, Periódico de Ciencia, Literatura y Bellas Artes (1839-1842), el motrileño llevó a cabo una revisión de la dramaturgia áurea en una sección titulada «Biografía de autores dramáticos españoles» y, tras publicar las fichas de los grandes dramaturgos de la época, en el número 38 del 20 de diciembre de 1840 aparecía, junto a Jerónimo Alonso de Salas Barbadillo y Francisco López de Zárate, Matías de los Reyes. A propósito de su comedia El agravio agradecido (publicada inicialmente en 1629 e incluida, posteriormente, en el Para algunos), Francisco Javier de Burgos la defendía como «la mejor escrita del teatro antiguo» (1840b: 445). Apenas tres días antes de la publicación aludida (el 17 de diciembre de 1840), el periodista granadino se ocupaba de Juan Pérez de Montalbán en la sección de biografías del periódico El Panorama dedicando 
buena parte de su atención al Para todos ${ }^{7}$ (1632), en cuya polémica mencionaba, entre los detractores, a «un licenciado pedante [...] de quien hablaremos en el artículo de Matías de los Reyes» (1840a: 4). Se trataba, sin duda -como viene a confirmarlo tres días después en La Alhambra- de don Gregorio Cid de Carriazo, prologuista del Para algunos.

Pese a que las aportaciones de Francisco Javier de Burgos no vienen a solucionar la dudosa relación entre las versiones de Matías de los Reyes y José Heriberto García de Quevedo, suponen la única referencia decimonónica al autor del Para algunos así como a esta obra en concreto, que abarca, como se decía, «La historia de los dos enamorados de la peña de Antequera». Por tanto, a falta de testimonios comunes que hablen en contra, los siguientes casos parecen demostrar la lectura de Matías de los Reyes en el seno del Romanticismo español por parte de García de Quevedo.

Líneas arriba quedaba plasmado el contexto social de la novela corta del seiscientos -de tintes boccaccianos- en el que don Tello, que hasta ese momento había vivido libre de los enredos de amor, había sucumbido a las condiciones de Ardama -«Ardana» en la novela de García de Quevedo- a partir de su descripción. Se trata, en esencia, del mismo esbozo que se halla en las primeras líneas de «La peña de los enamorados»:

una hermosa mañana de primavera, se hallaban reunidos en la plaza de Écija una porción de jóvenes de los más distinguidos de la ciudad, y lo que era muy propio de sus años, disputaban sobre la belleza, gracia y donaire de las damas andaluzas, procurando a porfía ponderar cada uno las prendas de la que había cautivado su corazón. [...] [don Tello] no se había cuidado del amor, y se había mostrado indiferente a las miradas de fuego de las damas andaluzas que más de una vez le habían manifestado que no les eran indiferentes sus nobles prendas y apuesta y gallarda figura (1850a: 29-30).

Más allá de esta convergencia, en episodios siguientes se vuelve a constatar el desapego de la novela de García de Quevedo con respecto al poema épico de Carvajal y Robles y, de otro lado, su afinidad con la novela corta de Matías de los Reyes. Así, una vez que don Tello ha conseguido pasar a servir en la casa de Abenabo (padre de Ardama) mediante la intercesión de Levi, la joven mora descubre la artimaña del modo que sigue:

[63] Pasaron por los dos algunos días siempre sufriendo, de su amor callado en las almas, secretas agonías

7 Curiosamente, Francisco Javier de Burgos compuso una comedia titulada Desengaños para todos (Morán 1986: 67). 
y confuso temor en el cuidado, hasta que de sentir melancolías, una noche, el amante desdichado, contra Ardama empezó a formar querellas sin pensar que testigo fuese dellas.

[66] Mas Ardama, que siempre le acechaba por un breve resquicio, las oía, que sobre el aposento que habitaba Tello, de su recámara se abría. Ella con atención las escuchaba y él con grave dolor las repetía, y mientras su mal cuenta dolorido ella lo va escribiendo en su sentido (2000: 150)

En este caso, la revelación inconsciente de la verdad responde a una escucha casual dada la contigüidad de las habitaciones de Tello y Ardama. Caso bien distinto al de la novela corta de Matías de los Reyes donde la joven musulmana, tras enamorarse perdidamente del pseudoesclavo que cuida su jardín,

un día tuvo favorable la ocasión de hallarse a solas con Levi [...] Sacó del informe del hebreo mucho más de lo que esperaba de las calidades de don Tello, demás de lo cual le refirió cómo por verla, enamorado de la relación que él mismo había hecho de su hermosura, se había fingido esclavo y dádole a él orden para que le vendiera a su padre, significándola cuán grandes demostraciones de amarla había reconocido en él. [...] Muy pagada quedó Ardama con nuevas tan a su propósito [... y por no le descubrir al judío de todo punto su pecho le despidió (1640: 77r).

En la versión de García de Quevedo es también Levi el encargado de interceder entre los enamorados:

Levi, que había ya conocido de un modo indudable, que a la hija de Abenabo no le era indiferente su esclavo, [...] le contó entonces minuciosamente cuanto había pasado con don Tello, y concluyó arrojándose a los pies de Ardana [...]. Ardana, cuyas mejillas durante la explicación de Levi habían pasado de una palidez suma al más encendido carmín, cuyos ojos habían brillado de placer al oír los trasportes de amor de su jardinero, envanecida con el cariño de un joven tan noble, discreto y arriesgado, faltó muy poco para que confesara que también ella amaba ciegamente; pero pudo dominarse (1850a: 34-35).

Amén de los casos mostrados, el episodio siguiente refleja de manera nítida la lectura que García de Quevedo debió de efectuar sobre la obra de Matías de los Reyes. En el seno de la trama, don Tello, aprovechando la oscuridad de la noche, se encarama a un árbol del jardín -planta ausente en el poema épico, que consiste 
en un moral en el caso del Para algunos y en un limonero en la versión romántica- para contemplar desde el mismo a su enamorada. En la versión del seiscientos, habiendo trepado Tello el moral,

quiso buscar medio como divertirla el sueño, y reparando que [...] sobre un cojín de terciopelo carmesí dormía una perrica de falda, [...] determinó inquietarla para que a su ruido ella despertase. Cortó para hacerlo una rama de aquel árbol con que asombrando la perrilla la obligó a retirarse ladrando a la cama de su dueño. [...] La perrilla, recogida al asilo de los brazos de su señora, se quietó y ella sin inquirir la causa de su inquietud prosiguió en su sueño (1640: 78r).

García de Quevedo, a propósito de don Tello, cuenta que

Una noche cuando ya todos dormían, se decidió a trepar por el árbol y acercarse a la ventana que estaba abierta [...] mas apenas lo había verificado, cuando una perrita que dormía en la habitación de Ardana, viendo que las ramas inmediatas se movían, comenzó a ladrar tan desaforadamente, que don Tello temió que despertase a todos y le descubriesen [...]. Mas por fortuna la perra asustada se refugió en el lecho de su ama, que aunque despertó no hizo caso de su ladrido (1850a: 35-36).

El árbol del jardín, en ambas versiones, acaba convirtiéndose en un aliado de don Tello, que sacia de esta forma las vistas de su amada, a pesar de que no vuelve a intentar despertarla hasta que la casualidad le brinda la ocasión oportuna: tanto Abenabo, padre de Ardama, como Zoraida, su aya -omitida, también, en la versión de Rodrigo de Carvajal y Robles-, han de ausentarse de la casa de Ardama. Esa misma noche don Tello ejecuta el cumplido ascenso, despierta a la joven y ambos mantienen una conversación amorosa, si bien Ardama le pide pronto que no arriesgue su vida, que descienda del árbol y que postergue la ocasión hasta mejor oportunidad para tratar de sus amores, aviso que culmina con un inesperado desenlace. En la narración de Matías de los Reyes:

queriendo don Tello ejecutar su mandamiento, trató de descender del empinado moral [...] pero la turbación gobernó tan mal sus pasos, que falseando una rama, vino precipitado, sin reparo alguno al suelo, lo cual conocido por Ardama [...] tuvo por cierta su muerte. [...] Se acordó que cerca de su cámara se bajaba por un secreto caracol a unas oscuras bóvedas, que con escasa luz de día eran alumbradas por unas lumbreras, que al mismo jardín salían (1640: 79v).

Semejante desatino tiene lugar en la novela romántica, donde don Tello,

deseoso de cumplir con presteza la orden que acababa de intimarle, perdió el equilibrio, se agarró a una rama demasiado débil, que desgajándose cayó con él al 
suelo, contra el que recibió un golpe mortal. [...] Ardama entretanto sufría horriblemente: se hallaba en una perplejidad congojosa, y no acertaba lo que debía hacer. [...] recordó una escalera lóbrega medio destruida y abandonada que desde su cuarto comunicaba con el jardín. ¡Bendito sea Alá! Exclamó, y tomando un pomo de bálsamo, sin asustarse por la lobreguez de las bóvedas que tenía que cruzar [...] bajó por la escalera oculta (1850b: 63).

Solventado este aparatoso trance, los amantes continúan comunicándose hasta que planean su huida desde la quinta de Abenabo, fuga que culminará de manera funesta. Ambos aspectos se tratan de forma muy similar en las versiones de Rodrigo de Carvajal y Robles y Matías de los Reyes, mientras que la narración de García de Quevedo difiere de aquellas sensiblemente en este último lance (Jiménez Morales 1996: 234). Cuando los jóvenes se hallan inmersos en una intensa persecución por parte de Abenabo y sus tropas, acorralados en la parte superior de la peña de Antequera, comienzan a ser atacados vigorosamente por arqueros. Tello y Ardama, conscientes de que no hay esperanza, optan por la siguiente solución en el Poema del asalto y conquista de Antequera:

[36] [...] y en dos recíprocos abrazos no con ánimos tristes, sino ledos, lían sus cuerpos en sus propios brazos y los trabados ñudos de sus dedos; y sin desbaratar los fuertes lazos, ni de la muerte recelar los miedos, de la tajada peña se arrojaron y en el aire las almas se dejaron [...] [39] En el río, que siempre los pies lava de la peña, cayeron abrazados, y casi la corriente se quejaba de verlos en sus ondas ahogados, que la sangre que dellos reventaba teñía sus raudales plateados de coral, porque fuese el agua roja publicando el color de su congoja (2000: 166).

De manera análoga, en la novela corta de Matías de los Reyes se evidencia la impronta de las estrofas aludidas de Rodrigo de Carvajal y Robles:

Y diciendo así, como estaban abrazados en indisoluble nudo, y con indecible constancia se arrojaron por lo más precipitoso de la peña, y dejando los espíritus amantes (si no católicos) en los vientos, no pararon hasta dar en los cristales del río, que 
al modo deste lava los pies a la encumbrada peña, convirtiéndolos en corales rojos (1640: 84r-v).

Si bien en ambas recreaciones los amantes se muestran unánimes en su resolución, García de Quevedo modifica este trágico suceso, pues en la narración romántica es Ardana quien toma la iniciativa optando por el suicidio colectivo y así lo ejecuta:

don Tello que la había escuchado con asombro, la estrechó contra su pecho, y entonces ella haciendo un esfuerzo que el joven no pudo resistir, se precipitó con él por la cortadura de la peña, y aquellos dos tan felices como infortunados amantes, fueron rodando hasta lo más profundo del valle, al que llegaron horrorosamente mutilados (1850b: 68).

En suma, valgan los pasajes confrontados para ratificar la huella de la novela corta de Matías de los Reyes - portadora, a su vez, de una variada tradición previa- en la novela romántica de García de Quevedo. Este hecho demuestra no solo la continuidad de la leyenda sino también la complejidad de su proceso de formación, en tanto que cada nueva versión aporta trabazón y densidad narrativas a la tradición a la que se adscribe, fórmula que comparten todas las manifestaciones literarias unidas mediante algún vínculo a la tradición oral y presas, por tanto, en variantes.

\section{CONCLUSIONES}

Todo lo dicho da cuenta de la pervivencia a lo largo de muchos siglos y en distintas versiones de una de las leyendas moriscas de más arraigada tradición, la peña de los enamorados de Antequera.

Matías de los Reyes, cuya personalidad literaria se nutrió de reescrituras, insertó en su obra más ambiciosa, el Para algunos, el primer testimonio en prosa de ficción de la leyenda, que tomó del Poema heroico del asalto y conquista de Antequera de Rodrigo de Carvajal y Robles que, a su vez, entroncaba con la tradición abierta por Lorenzo Valla y divulgada por Juan de Mariana. No obstante, el autor del Para algunos no se ciñó únicamente a la gesta en octavas sino que, tal y como se ha probado, atavió su novela corta con remiendos de otros escritos. Al mismo tiempo y, a pesar de este afán emulador, Matías de los Reyes aportó novedades a la trama de su novela corta, innovaciones que han pasado inadvertidas pero que constatan la lectura y el influjo de este autor madrileño en una de las múltiples versiones que se gestaron en el Romanticismo español tras la eclosión de este motivo fronterizo, la de José Heriberto García de Quevedo, que, pese 
a que tomó como testimonio predilecto el poema épico de Carvajal y Robles, se surtió de buena parte de las aportaciones con las que Matías de los Reyes había timbrado la leyenda.

En este sentido, parece osado formular cualquier hipótesis que hermane el concepto de originalidad con la literatura de Matías de los Reyes, habida cuenta de la trayectoria y el modus scribendi del autor. Por el momento, los resultados expuestos son fruto de un análisis textual no conclusivo ni exclusivo sino abierto a la posibilidad del hallazgo de nuevos testimonios que reformulen lo aquí presente. Pese a esta contingencia, la nutrida red de relaciones que se establece en la confrontación de solo tres versiones de la leyenda manifiesta la dificultad que entraña el conocimiento exhaustivo de todos los moldes literarios que la han abordado, así como de los diversos y complejos vínculos que entre ellos han quedado urdidos.

\section{BiBLIOGRAFÍA}

Alemán, Mateo (2009). Guzmán de Alfarache. José María Micó (ed.). vol. I. Madrid: Cátedra. Boccaccio, Giovanni (2001). Decamerón. María Hernández (ed.). Madrid: Cátedra.

Bondía, Ambrosio (1650). Cítara de Apolo y Parnaso en Aragón. Zaragoza: Diego Dormer. Burgos, Francisco Javier de (1840a). «Biografía. El doctor Juan Pérez de Montalbán». El Panorama, 103, pp. 385-388.

— (1840b). «Biografía de autores dramáticos españoles. Matías de los Reyes. Gerónimo Alonso de Salas Barbadillo. Francisco López de Zárate». La Alhambra. Periódico de Ciencias, Literatura y Bellas Artes, 38, pp. 445-446.

Carrasco Urgoiti, María Soledad (1989). El moro de Granada en la literatura (del siglo XV al XIX). Granada: Universidad de Granada.

Carvajal y Robles, Rodrigo de (2000). Poema heroico del asalto y conquista de Antequera. Bautista Martínez Iniesta (ed.). Málaga: Servicio de Publicaciones de la Universidad de Málaga.

García de Quevedo, José Heriberto (1850a). «La peña de los enamorados. Tradición del siglo xv» (I-II). Museo de las Familias, tomo VIII, 4, pp. 29-36.

(1850b). «La peña de los enamorados. Tradición del siglo XV» (III). Museo de las Familias, tomo VIII, 7, pp. 63-69.

García de Yegros, Alonso (1915). Historia de la antigüedad y nobleza de la ciudad de Antequera. Antequera: El Siglo XX.

Jiménez Morales, María Isabel (1996). «La leyenda de la Peña de los enamorados en textos literarios no dramáticos del siglo XIX». Revista de Estudios Antequeranos, 7-8, pp. 215-249.

LARA GARrIDO, José (1982). «Tres poemas inéditos del XVII en manuscritos antequeranos». Analecta Malacitana: Revista de la Sección de Filología de la Facultad de Filosofía y Letras, vol. 5, 1, pp. 173-188.

(1984). «En torno a un nuevo romance inédito sobre la leyenda fronteriza de la Peña

Edad de Oro, XXXV (2016), pp. 251-267, ISSN: 0212-0429 
de los enamorados». Analecta Malacitana: Revista de la Sección de Filología de la Facultad de Filosofía y Letras, vol. VII, 1, pp. 142-148.

Martínez Bennecker, Juan Bautista (2008). «La poesía de senectud de Juan Bautista de Mesa», Lemir, 12, pp. 235-254.

Martos Pérez, María Dolores (2008). La obra poética de A. de Tejada Páez: estudio y edición. Lara Garrido [tesis doctoral]. Málaga: Universidad de Málaga.

MenÉndez ArAngo, Miguel (1842). «El ingrato por amor. Novela histórica». El Nalón de Oviedo, 6, pp. 87-91.

Menéndez Pelayo, Marcelino (1944). Antología de poetas líricos castellanos, vol. VII. Santander: Aldus.

Miranda ValdÉs, Javier (2005). Aureliano Fernández Guerra (1816-1894), un romántico, escritor y anticuario. Madrid: Real Academia de la Historia.

Molina, Tirso de (1994). Obras completas. Pilar Palomo, Isabel Prieto (eds.). Madrid: Turner.

Morán, Manuel (1986). «Notas para un catálogo de los escritos literarios de Javier de Burgos». Rilce, II, 1, pp. 61-72.

Moreno, Modesto (1891). «Bibliografía de "La peña de los enamorados"». El Ateneo de Málaga, nº 545, pp. 3-4.

Ossorio y Bernard, Manuel (1903). Ensayo de un catálogo de periodistas españoles del siglo XIX. Madrid: Imprenta y litografía de J. Palacios.

Reyes, Matías de los (1640). Para algunos. Madrid: Viuda de Juan Sánchez.

Roca de Togores, Mariano (1836). «La peña de los enamorados». Semanario Pintoresco Español, 24, pp. 93-195.

RodríguEz GutIÉRrEZ, Borja (2002). «Dos narraciones románticas del siglo XVIII». Dieciocho. Hispanic Enlightenment [separata], vol. 25, 1, pp.121-142. (2004). Historia del cuento español (1764-1850). Madrid: Iberoamericana.

Talavera Esteso, Francisco J. (1995). «Sobre la peña de los dos enamorados que se halla junto a Antequera. Al destacado escritor don Fabián de Nebrija». El humanista Juan de Vilches y su De variis Lvsibvs Sylva, Analecta Malacitana, Anejo VII, pp. 265287.

Tejada PÁez, Agustín de (2005). Discursos históricos de Antequera. Asunción Rallo Gruss (ed.). Málaga: Diputación Provincial de Málaga.

ZúÑIgA, Manuel de (1839). «La peña de los enamorados». La Alhambra: Periódico de Ciencias, Literatura y Bellas Artes, ${ }^{\circ}$ 5, pp. 80-83.

Valla, Lorenzo (1957). La conquista de Antequera, con la leyenda de la Peña de los enamorados. José López de Toro, Francisco López Estrada (eds.). Antequera: G. E. H. A.

Recibido: 15/7/2016

Aceptado: 1/10/2016 


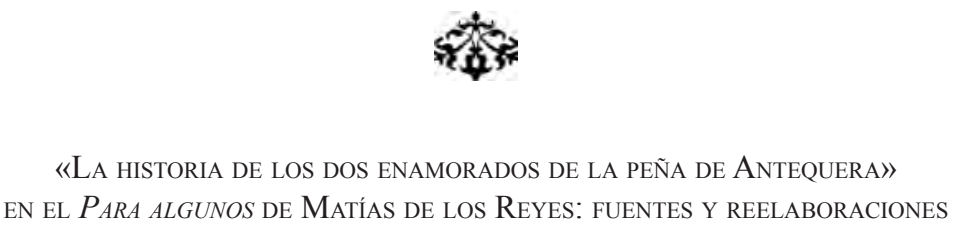

Resumen: En «La historia de los dos enamorados de la peña de Antequera», novela corta incluida en el Para algunos (1640), Matías de los Reyes recreó una célebre leyenda de asunto fronterizo a partir del Poema heroico del asalto y conquista de Antequera (1627) de Rodrigo de Carvajal y Robles. A su vez, una de las versiones decimonónicas de la misma leyenda, la novela por entregas de José Heriberto García de Quevedo «La peña de los enamorados» (1850), evidencia la lectura y proyección de la novella de Matías de los Reyes en pleno Romanticismo español.

Palabras Clave: peña de Antequera, Para algunos, Matías de los Reyes, novela corta, García de Quevedo, leyenda fronteriza, Romanticismo.

\section{«LA HISTORIA DE LOS DOS ENAMORADOS DE LA PEÑA DE ANTEQUERA» in MATías DE LOS REYES' Para ALgunos: SOURCES AND REWRITES}

Abstract: Matías de los Reyes included in Para algunos (1640) the short novel «La historia de los dos enamorados de la peña de Antequera», leyend based on a frontier topic whose main source was Poema heroico del asalto y conquista de Antequera (1627) of Rodrigo de Carvajal y Robles. Furthermore, one of the leyend's nineteenth-century versions, José Heriberto García de Quevedo's «La peña de los enamorados» (1850), shows the reading and influence of Matias de los Reyes 'novella in the Spanish Romanticism.

Keywords: Antequera's hill, Para algunos, Matías de los Reyes, short novel, García de Quevedo, leyends based on frontier topic, Romanticism. 
Miguel de Cervantes (1547-1616)

Pierre Darnis (Université Bordeaux Montaigne)

Don Quijote: ¿andante caballero o maleante andariego?

Para una lectura «superficial» (y esencial) de El ingenioso hidalgo

don Quijote de la Mancha (1605)

Valentín NúÑEz Rivera (Universidad de Huelva)

La poética pastoril de don Quijote (y de Cervantes): una latencia interrumpida ..... 57

Silvia Esteban Naranjo (Universidad Autónoma de Madrid)

Las entradas y salidas de los personajes en la Numancia de Cervantes.

Fernando Romo Feito (Universidade de Vigo)

Un epigrama latino para Cervantes (Viaje del Parnaso)........................................... 87

José Solís de Los SANTos (Universidad de Sevilla)

Cervantes y el entorno humanista de los Ramírez de Prado

Francisco Cuevas Cervera (Universidad de Chile)

Lecturas decimonónicas de la segunda parte del Quijote: una aparente

paradoja del cervantismo romántico

Alexia Dotras Bravo (Instituto Politécnico de Bragança)

La recepción de Miguel de Cervantes en el Portugal contemporáneo

María Fernández Ferreiro (Universidad de Oviedo)

Dos centenarios quijotescos en el teatro: 2005 y 2015

JAMES IFFLAND (Boston University)

A otro perro con esos huesos: reflexiones sobre el cervantismo osteológico 159

\section{OtRos TEMAS}

Daniel Fernández Rodríguez (Universitat Autònoma de Barcelona)

Una fuente olvidada del Guzmán de Alfarache: la novella de «Dui giovani

sanesi» de Parabosco (y unas notas sobre Masuccio, Sansovino y Tamariz) ......... 175

Jaime José Martínez Martín (UNED)

El prólogo «Al lector» de Mira de Amescua y la teoría de la égloga

en Siglo de Oro en las selvas de Erifile de Bernando de Balbuena 191

Manuel Asensi Pérez (Universitat de Valéncia-Estudi General)

Modelos de mundo y violencia en los Comentarios reales del Inca Garcilaso. 
DANiEl Waissbein

Góngora, príncipe de los poetas, y su aparente alabanza del Faetón de Villamediana.

José Luis Losada Palenzuela (Universidad de Wrocław)

El toro y el héroe: variación del motivo en la narrativa

de Juan Enríquez de Zúñiga

Alba Gómez Moral (UNED)

«La historia de los dos enamorados de la peña de Antequera»

en el Para algunos de Matías de los Reyes: fuentes y reelaboraciones

TEXTOS INÉDITOS

Esther Fernández LóPez (Universitat de Valéncia)

La Dánae burlesca de Pedro Silvestre. Edición anotada 271

NORMAS DE ENVÍO Y ADMISIÓN DE ORIGINALES 
Miguel de Cervantes (1547-1616)

PIERre Darnis (Université Bordeaux Montaigne, AMERIBER)

Don Quixote: Knight-errant or Errant Malefactor? For a Superficial

(and Essential) Reading of The ingenious Gentleman Don Quixote

de la Mancha (1605)

VALENTín NúÑEZ RIVERA (Universidad de Huelva)

The pastoral poetry of Don Quixote (and Cervantes): an interrupted latency.

Silvia Esteban Naranjo (Universidad Autónoma de Madrid)

The go in and the go out in the roles of Cervantes' Numancia

Fernando Romo Feito (Universidade de Vigo)

A Latin epigram for the Viaje del Parnaso by Cervantes

José Solís de los Santos (Universidad de Sevilla)

Cervantes and the humanist circle of the Ramírez de Prado

Francisco Cuevas Cervera (Universidad de Chile)

Nineteenth-century readings of the second part of Quixote:

Apparent paradox in the Romantic Cervantism.

Alexia Dotras Bravo (Instituto Politécnico de Bragança)

Reception of Miguel de Cervantes in contemporary Portugal

María Fernández Ferreiro (Universidad de Oviedo)

Two quixotic centenaries in theatre: 2005 and 2015

JAMES IfFLAND (Boston University)

Throw those bones to another dog: reflexions on Osteological Cervantism 159

\section{OTHER THEMES}

Daniel Fernández Rodríguez (Universitat Autònoma de Barcelona)

A forgotten source of Guzmán de Alfarache: the novella about «Dui giovani sanesi» by Parabosco (and some notes regarding Masuccio, Sansovino and Tamariz) ..... 175

Jaime José Martínez Martín (UNED)

The prologue «Al lector» of Mira de Amescua and the Eclogue Theory

in Siglo de Oro en las selvas de Erifile of Bernando de Balbuena

Manuel Asensi Pérez (Universitat de Valéncia-Estudi General)

World models and violence in the Comentarios reales of the Inca Garcilaso. 
DANiEl Waissbein

Góngora, prince of the poets of Spain, and his and his supposed encomium of Villamediana's Phaeton

José Luis Losada Palenzuela (Universidad de Wrocław)

The Bull and the Hero: variation of the motif in the prose fiction

of Juan Enríquez de Zúniga

Alba Gómez Moral (UNED)

«La historia de los dos enamorados de la peña de Antequera»

in Matias de los Reyes' Para algunos: sources and rewrites.

UNPUBLISHED TEXTS

Esther Fernández López (Universidad de Valencia)

The burlesque Danae by Pedro Silvestre. An annotated edition 271

CRITERIA FOR SENDING AND ACCEPTING MANUSCRIPTS 


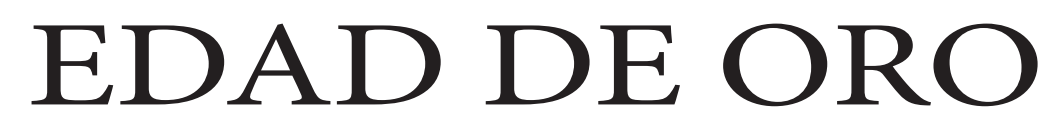

Revista de Filología Hispánica XXXV

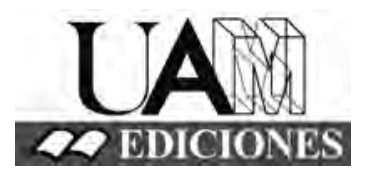




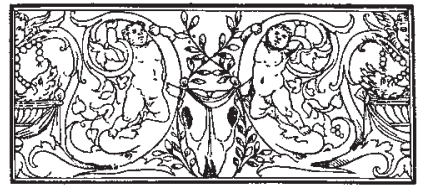

\section{Edad de Oro. Revista de Filología Hispánica}

ISSN: 0212-0429

Dirección:

Teodosio Fernández

Secretaría y edición:

José Ramón Trujillo

Comité científico internacional:

Carlos Alvar (Univ. de Ginebra)

Ignacio Arellano (Univ. de Navarra)

Javier Blasco (Univ. de Valladolid)

Alberto Blecua (UAB)

Jean Canavaggio (Univ. de París X)

Laura Dolfi (Univ. de Turín)

Aurora Egido (Univ. de Zaragoza)

Víctor García de la Concha (RAE)

Luciano García Lorenzo (CSIC)

Joaquín González Cuenca (Univ. de Castilla-

La Mancha)

Agustín de La Granja (Univ. de Granada)

Begoña López Bueno (Univ. de Sevilla)

Michel Moner (Univ. de Toulouse III)

Joan Oleza (Univ. de Valencia)

Alfonso Rey (Univ. de Santiago)

Lina Rodríguez Cacho (Univ. de Salamanca)

Leonardo Romero Tobar (Univ. de Zaragoza)

Aldo Ruffinatto (Univ. de Turín)

Lía Schwartz (City University of New York)
Redacción y admisión de originales:

Teodosio Fernández

Edad de Oro

Departamento de Filología Española

Universidad Autónoma de Madrid

28049 Madrid (España)

Tfno.: +0034 914974090

correo: teodosio.fernandez@uam.es

Distribución, suscripción y venta:

Servicio de Publicaciones de la UAM

Universidad Autónoma de Madrid

28049 Madrid (España)

Intercambio de publicaciones:

Biblioteca de la Facultad de Filosofía y

Letras (UAM)

Universidad Autónoma de Madrid

28049 Madrid (España)

Han colaborado en este volumen:

Departamento de Filología Española (UAM)

Facultad de Filosofía y Letras (UAM)

Edad de Oro se recoge, entre otras, en las siguientes bases de datos: SCOPUS, MLA Database, HLAS, Latindex, PIO-Periodical Content Index, ISOC, Dialnet, MIAR, ERIH, DICE, Sumaris CBUC, Ulrich's. Se encuentra evaluada en CIRC: A; MIAR difusión ICDS live 2016: 10.0; INRECH; SCImago Journal \& Country Rank: H Index 3, SJR 0,1, Q4; RESH índice de impacto: 0.041; ERIH: A INT1; Carhus Plus+ 2014: C. 